\title{
REFORMAS Y ORALIDAD EN EL PROCESO
}

\section{Luis Gonzalo Navarrete Villegas \\ Prof. Universidad de Concepción}

Desde el código austríaco de Klein ha venido reiterándose el que la manera de simplificar el proceso y hacerlo más accesible a los justiciables, es la sustitución del principio de la escritura por el de la oralidad.

Las ventajas de la oralidad parecen evidentes y han sido expuestas por la doctrina: mayor brevedad del proceso, más inmediación del juez (subjetiva y objetiva), más cercanía del justiciable a la justicia, menor costo económico, una vez más garantizada publicidad y ejemplaridad de la función jurisdiccional, etc. Como ejemplos se citan el proceso austríaco y el proceso anglosajón.

Tal importancia se dio a las oralidad que en la constitución española de 1978 se dispone en el inciso segundo del artículo 120 que" El procedimiento será predominantemente oral, sobre todo en materia criminal".

Sin embargo, cabe preguntarse con qué circunstancias o garantías debe ser implantado el principio de oralidad para que se obtengan los beneficios que del mismo se pretenden, pues es innegable que el principio por si mismo no resuelve todos los males ni desigualdades que aquejan al proceso y a las partes, y que dicho principio, unido a los actuales defectos de funcionamiento del proceso, puede ser un factor más de distorsión que de arreglo y mejoramiento del proceso.

Con la complejidad de las relaciones, los intereses en juego, con el número cada vez mayor de litigantes que hacen aumentar la acumulación de causas sobre la mesa de cada juez, con los jueces llamando a las partes a comparecer y escuchándolas oralmente, es ingenuo pensar que van a poder dictar sentencia no ya justa, sino medianamente razonada.

La implantación de la oralidad exige unos requisitos inexcusables que, por lo demás, se respetan en aquellos países en que este principio en verdad se aplica.

En primer término, se necesita un número suficiente de tribunales y jueces ante los cuales puedan efectivamente celebrarse los juicios con una debida ponderación y estudio, 
En segundo lugar, una preparación previa de la vista oral ante el Secretario del Tribunal, como en el Derecho inglés, en la que las pruebas y contrapruebas de cada parte despejen las complicadas cuestiones de hecho y hagan más fácil la aplicación de las normas jurídicas; es decir, la preparación de las pruebas de que se van a valer en la vista oral, dirigiendo y canalizando los puntos de interés separándolos de los no pertinentes, accesorios y circunstanciales.

Por último, el juez debe estar dotado de amplios poderes directivos en la ordenación y dirección del debate, para hacer posible la rapidez y la inmediación subjetiva y objetiva que supone este principio. En virtud de estos poderes el juez sancionará al litigante que por no haber cumplido con ciertos deberes procesales (negativa injustificada a declarar, incomparecencias reiteradas y no justificadas, etc. ) provoque un retardo en el proceso; y en caso de mala fe o dolo procesales probados que hayan hecho imposible la administración de justicia, la sanción sea la pérdida del proceso por ese litigante.

Mientras no se den estos y otros supuestos que bien pueden enumerarse, la sustitución del principio de escritura por el de la oralidad no haría más que agravar los actuales y numerosos defectos que el proceso presenta. 